\title{
MASSED VS. DISTRIBUTED EFFORT IN LEARNING*
}

\author{
L. A. PECHSTEIN, \\ University of Rochester.
}

Ebbinghaus, Yost, Browning, Brown and Washburn, Murphy, Ulrich, Pechstein, Lashler, Carr and Cummins have contributed experimentally to the question whether it is more efficient to learn a problem with the learning effort being massed, i. e., continuous in time, or broken by periods of changed activity. Everyone contributing to the discussion agrees, in general, that distributed practice is more efficient than massed, the tendency being to generalize for various types of learning material, such as motor, nonsensical and meaningful. Specialized discussions by Carr (1) and Cummins (2) raise the question whether the efficiency of distributed effort is confined to certain stages in the learning process or whether this mode of acquisition is uniformly effective for all stages in the development of a habit, they answering that distributed effort is of greater effciency during the early stages. Lashley, Colvin and all educational psychologists comment upon the neurological aspects of distributed learning, although Lashley (3) seems to take exception to the doctrine of a gradual "setting" of the nervous connections between practice periods.

The purpose of this paper is to show that the entire question is tied up with a second, namely,-is the learning material mastered as a whole or in parts?

The experimentation is restricted to the field of motor learning, the learning problem being a very difficult maze reported three years ago (4). This maze subdivides into four sections highly comparable in basic features and difficulty, these being so arranged that the maze can be learned as a whole, in parts, or in any combination of parts. The learning criteria are the number of trials required to secure four out of five perfect runs, learning time and learning errors, the latter being those conventionally recorded in maze experimentation. The experimental technique is exactly the same as re ported in earlier articles.

Earlier experimentation with this particular maze naturally had shown that human adults learned the problem far more economically

- Read at the annual meeting of the American Peychological Association. December $28-30,1920$. 
when their effort was distributed at the rate of one trial per day rather than massed (5). In fact, the maze had proved too difficult for certain human subjects to learn under massed conditions. Also, it was shown to be more economical for these adults to learn their problem as a whole rather than to learn the four units separately, finally connecting them in serial order, provided the learning effort was distributed in each case. Because of the difficulty of the maze and the way in which the rat is organized, it was naturally impossible to secure massed learning results from the rats. The initial step of the present experiment was to shorten the maze problem, hereby to discover whether rats could be taught a simple problem under massed requirements; subsequently, to study human learning under comparable conditions.

Because the particular maze used in my whole-part experimentation is made up of four short and separate maze units, these simple units were employed to test the capacity of the rat to learn under massed conditions. After being handled and fed in the food box for a standardized period of 10 days, feeding was skipped for 48 hours, whereupon the training was begun. Each rat learned the first short maze section with apparent ease, although the amount of learning effort expended far surpassed what $I$ had supposed the white rat capable of continuously directing. A short feeding was allowed after all in the group had mastered the first section. On the following day Section II was learned with ease under massed conditions, this being followed by the mastery of Sections III and IV upon the third and fourth day, respectively.

Upon the day following the learning of the last section, each rat was set the problem of connecting the units into proper serial order. Not only did each member of the group effect the perfect connections under massed conditions, but several made the complex step without securing a single error. Herein is the most striking feature of the entire situation. When humans or rats are taught these short units under distributed conditions, the complex act of connection proves extremely difficult. When these units are learned under massed conditions, not only is this first learning task easy, but the hard act of connection becomes extremely simple.

Comparable results held when human adults were tested under like temporal conditions. 
An inspection of Table I points the way to several significant conclusions :

TABLE I.-A table to show the mean number of trials, time and errors of two groups of rats (nine per group) and two groups of humans (six per group) in learning Maze A by the "part" method. The records for distributed learning appear first in each section, the massed learning records second. The third item in the total is for groups learning the Maze as a whole under distributed conditions, the last as a whole under massed conditions. For estimating total runs, each sectional run is counted as one-fourth the entire (I-IV) run.

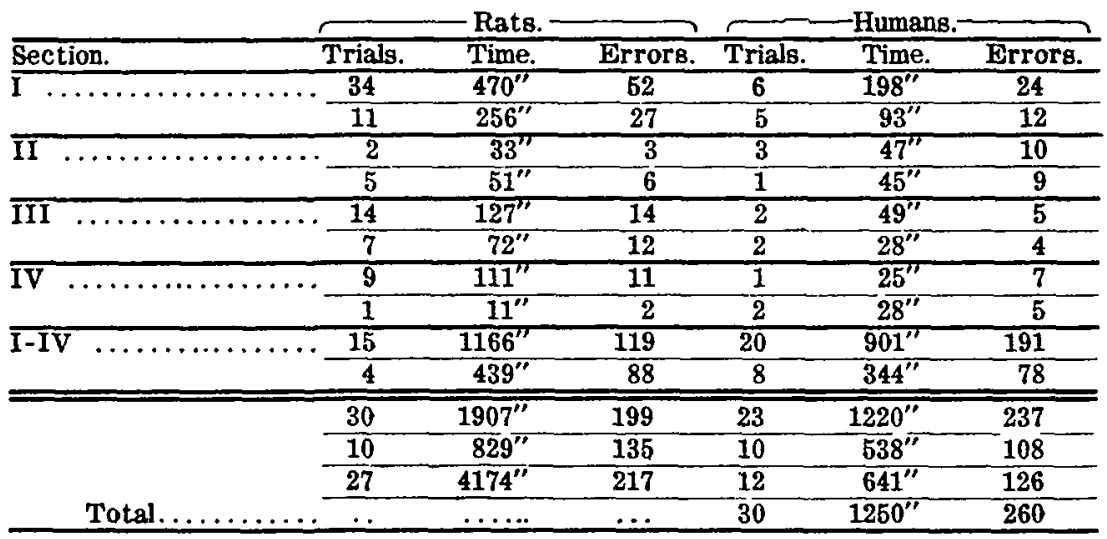

First, provided the maze problem is short, it is more economical to mass learning effort than to distribute it, irrespective whether economy is estimated in terms of trials, time or errors.

Second, for subsequently learned short runs (allowing transfer possibilities), massed effort continues, in general, to be preferable, it hereby appearing that, if problems are thoroughly learned before subsequent ones are undertaken, the transfer is positive rather than negative.

Third, in connecting short maze patterns learned as separate units, the complex act of connection is not only possible in a massed program, but is accomplished with very great economy, just so long as the units have been learned as massed effort problems.

Fourth, the longer and more difficult the problem, the more advisable to break it up into units and learn both the units and the connection of these under massed conditions, it being uneconomical to learn the hard problem as a whole, irrespective whether effort is massed or distributed. 
Fifth, it is clear that the question of massed vs. distributed learning is tied up with the question whether the difficult problem is to be learned as a whole or in parts. The hard problem becomes easy if it is learned under massed conditions by the part method and in no other way; it remains hard if it is learned as a whole under massed or distributed conditions, or even in parts under distributed conditions.

Sixth, these results hold for motor learning of the maze type, both for selected animals and the human adult.

The explanation of the conclusions is not far to seek. It is not necessary to comment upon the advantages inherent in any part method, such as the full utilization of transfer possibilities, the diminishing returns secured as the problem is lengthened, etc., since these are, presumably, fairly constant under both massed and distributed learning. It is essential to show why an easy problem is best learned under massed conditions and why several so learned can readily be united through massed effort. Explanation rests here, I believe, upon two principles operative in all learning.

The first of these is the principle of elimination. "It connotes the detection of critical points in the problem, the careful study of all the details, the formation of proper associations, the rejection of others, etc. Consciousness is heqre at white-beat. The longer and more difficult the problem, the greater the task upon the learner to see the many details of the problem and to learn to eliminate the possible faulty reactions. Confusion, hesitation, emotional conditions all operate to delay the learning" (6). If the problem is short and easy, the principle of elimination operates with maximum effectiveness. No emotional complex is aroused to disturb the organism in utilizing all his problem-solving, adjustmental powers; the relative fewness of possible errors makes these lie within the organism's powers of mastery ; the learner has available the energy required for the successive explorative trials, and this is utilized; if given one trial only, the learner is far within the limit of his available strength. Massed effort upon a long and hard problem strains the power of the organism and elimination ceases to operate efficiently; massed effort upon an easy problem challenges the organism to work within normal and proper limits, and elimination operates efficiently; distributed effort upon an easy problem allows the eliminative principle to operate, but does not secure that total 
learning efficiency normally expected after the preliminary warming-up stage; distributed effort upon the hard problem gives opportunity for the eliminative principle to operate, but not always at its best, since the difficulty of the problem generally strains the organism beyond the normal limits of its power.

The second learning principle involved is that of mechanization. "This final stage of learning is no longer explorative and eliminative, but rather, mechanizing and rendering habitual the entire activity. Whole method learning presents so many critical details that the principle of mechanization is not only delayed in being given an opportunity to operate, but is repeatedly nullified by the re-injection of the highly conscious eliminative principle" $(6)$. This condition maintains both for massed or distributed attack upon the hard problem. The part method utilizes the two methods to best advantage. The explorative or eliminative principle is operative when the details of the short and easy parts are being grasped, it being made clear that the best elimination is secured by massing the learning of each short part. Then the time becomes ripe, logically and psychologically, for the mechanizing principle to operate. It secures the mechanization of each unit and their connection, herein being concerned only with rapidly welding the several unit habits. Psychologically speaking, the runner who hesitates in this stage is lost. By rapid and consecutive runs he forced the required union. Fortunately, if he has learned the units as massed problems, his act of connection is rery easy, while it is extremely difficult if the unit habits are set up under distributed conditions. Why? Because in working steadily through a massed period upon short problems he has come to set up habits of long application, exactly what is required for the complex act of connection. The distributing learner, only having one trial per day upon short units, has acquired habits of short application, these almost rendering impossible the final connection and mechanization of the units into a perfect total habit.

The whole method never secures complete utilization of the principles of elimination and mechanization, the loss being greater for massed learning. The part method secures full utilization of the principles, provided the learner masses his effort.

Part method and massed learning-so long anathema to the pure and educational psychologist-may not be understood one apart 
from the other; employed together, they make the best arrangement for learning difficult motor problems.

\section{BIBLIOGRAPHY.}

1.-Carr, Harvey. Distribution of Effort. Psych. Bull, 16, 1919, 26.

2.-Cummins, R. A. Improvement and the Distribution of Practice. Teachers College, Columbia University, Contribution to Education. No 97 (1919).

3.-Lashley, K. S. A Simple Maze: With Data on the Relation of the Distribution of Practice to the Rate of Learning. Psychobiology, I, 5, 1918, 353.

4.-Pechstein, L. A. Alleged Elements of Waste in Learning a Motor Problem by the Part Method. Jr. Ed. Psychol., 1917, VIII, 303.

5.-Pechstein, L. A. Whole vs. Part Methods in Motor Learning. A Comparative Study. Psychol. Rev. Mon. Supp, Vol. XXIII, No. 2, pp. 59 sq.

6. Pechstein, L. A. Whole vs. Part Methods in Learning Nonsensical Syllables. Jr. Ed. Psychol., 1918, IX, 387. 